\title{
Editorial for Earth, Moon, and Planets
}

\author{
Murthy S. Gudipati
}

Published online: 18 July 2009

(C) Springer Science+Business Media B.V. 2009

\section{Dear Colleagues,}

It is my pleasure to introduce myself as the incoming Editor-in-Chief of Earth, Moon, and Planets. I will be sharing this responsibility with continuing Editor-in-Chief Giovanni Valsecchi. I also thank Mark Bailey for his support/contributions to this journal.

First, a few words about myself. I am a principal scientist at the NASA Jet Propulsion Laboratory of the California Institute of Technology. Presently my research is focused around the evolution of ices in the Universe. In my laboratory at JPL, we conduct laboratory simulations on ice-analogs to understand their physical and chemical properties, their spectroscopic properties from vacuum ultraviolet to far-infrared, and apply these data to interpret/guide astrophysical observations.

I was born in a remote village in southern India, climbed the trees, and watched the stars and snakes during my early years in these villages. I went to college in Vijayawada, got a Master's at the University of Hyderabad, a Ph.D. at the Indian Institute of Science, Bangalore, and Habilitation at the University of Cologne, Germany. I was a post-doctoral fellow at UT Austin, visiting scientist at Fritz-Haber-Institute, Freie Universitaet Berlin, NASA Ames Research Center, and SRI International. I'm also on the faculty of the University of Maryland, at College Park.

As my work at JPL and elsewhere can attest, we are living in an era of expanding space sciences-similar to what physics enjoyed towards the beginning of last century. Very successful missions to Mars and the outer planets in the past decade or two (Galileo and Cassini) shifted the space sciences paradigm from remote sensing to in situ robotic explorations. Even after 5 years of a successful mission, rovers Spirit and Opportunity are still speeding around on Mars. The science of the Moon is on the rise again, with a big paradigm shift here, too-international cooperation is the mantra-not competition as it used to be. This is another opportunity for the international science community to come together to achieve a goal that is far higher than the sum.

At this point, it is needless to say that the international community of planetary scientists needs a larger platform and an option to choose to publish their science. Most of us 
who publish scientific work know that an option to consider a couple of competing highimpact journals is highly desired. We all would like to see a fast and fair review process. We all would like the articles to be published within an acceptable time frame, say around 4 months after accepted. My goal as the Editor-in-Chief of Earth, Moon, and Planets is to achieve these reasonable goals and provide you with a journal that attracts high-quality planetary science articles. Towards this goal, I need your help, both as contributing authors and referees. Peer-review is the most important part of scientific publishing. We all are aware that in the recent years referees are hard to get and they feel neglected. We are working on incentives to acknowledge the efforts put by the referees in reviewing the articles.

Let's work together to bring an outstanding journal to the planetary science community.

Please send me an e-mail if you have suggestions and if you would like to help as a referee. 